\title{
SIMULATION MODEL OF PUMPED HYDROELECTRIC POWER PLANT
}

\author{
Miroslav MIKITA, Michal KOLCUN \\ Department of Electric Power Engineering, Faculty of Electrical Engineering and Informatics, \\ Technical University of Košice, Letná 9, 04200 Košice, Slovak Republic, e -mail: \{miroslav.mikita, michal.kolcun\} @ tuke.sk
}

\begin{abstract}
Abstract The Pumped hydroelectric power plants are very suitable way to avoid the unpredictable imbalance in power generation, but it's construction is very expensive and reliability is very long-term. Every single pumped hydroelectric power plant is like rechargeable battery which can generate electricity when there is a deficiency in power generation and also can consume when there is conversely reserve on power generation. That's the main reason why is important to build such sources of energy. When you create new project of every power plant that prediction of it's performance is highly important and simulation software is useful in this cases. For good prediction is also important true data in simulation and knowledge about locality of this project, because every project varies from other similar projects. For obtaining optimal conditions of using pumped hydroelectric power plant is needed to find best algorithm of generating or consuming the electricity.
\end{abstract}

Keywords: pumped hydroelectric power plant; simulation; GoldSim;

\section{INTRODUCTION}

Water is the Earth and its atmosphere in constant motion. As a result of the activities of the Sun water evaporates from water surfaces, creating clouds of steam and falls to earth as rain or snow. The energy of this water cycle is a used effectively in water power plants.[1]

The use of water power to drive the mechanical equipment is very old activity and reaches far into the past. Simple water- powered mill wheels which replaced hard work were first used very long time ago.

The first mention of such equipment occurs in about Greeks 4000 years before AD, Greeks used hydro mainly for grinding grain.

This natural energy has become even easier and more widespread after what was developed the first water turbine in the early 19th century. From this period begins gradually promote electricity generation hydroelectric power stations.

Latest technology of electricity production from water are based on the using of marine tidal marine waves or temperature difference of water in the oceans. For these types of hydropower only tidal is not the result of activity of the Sun, but is caused by force of attraction of the Moon.

Wave energy is a direct result of wind, which is also caused by solar activity. The amount of energy contained in the Earth's water cycle is huge, but its use is technically difficult. Despite the fact that there are several ways to use energy of water, is the most widely used to direct production electricity from hydropower in water power plants.

\section{WATER ENERGY}

Hydropower potential at any point is given by two variables:

- Water flow rate, which is determined by the amount of water flowing through the profile per unit time. Flow unit is $\mathbf{m}^{\mathbf{3}} \cdot \mathbf{s}^{\mathbf{- 1}}$. Its variable depending on the intensity, duration and distribution of precipitation.
- Water gradient is the vertical height of drop of water. May be due to the natural slope of the terrain or usually is artificially created as a dam. Height of water gradient is affected by levels fall or rise in the reservoir dam. [1]

$\bullet$

a) Potential energy

Positional

$E_{h}=m \cdot g \cdot H \quad\left[\mathrm{~J} ; \mathrm{kg}, \mathrm{m} \cdot \mathrm{s}^{-2}, \mathrm{~m}\right]$

Pressure

$E_{p}=m \cdot \frac{p}{\rho} \quad\left[\mathrm{J} ; \mathrm{kg}, \mathrm{Pa}, \mathrm{kg} \cdot \mathrm{m}^{-3}\right]$

b) Kinetic energy

$$
E_{x}=\frac{1}{2} \cdot m \cdot v^{2} \quad\left[\mathrm{~J} ; \mathrm{kg}, \mathrm{m} . \mathrm{s}^{-1}\right]
$$

$$
\text { E } \quad \text { - energy [J], }
$$$$
m \quad \text { - weight }[\mathrm{kg}] \text {, }
$$$$
g \quad-\text { gravity acceleration }\left[\mathrm{m} . \mathrm{s}^{-2}\right] \text {, }
$$$$
H \quad \text { - water gradient [m], }
$$$$
p \quad \text { - pressure }[\mathrm{Pa}] \text {, }
$$$$
\rho-\text { density }\left[\mathrm{kg} \cdot \mathrm{m}^{-3}\right] \text {, }
$$$$
v \quad-\text { water speed }\left[\mathrm{m} \cdot \mathrm{s}^{-1}\right] \text {. }
$$

Water power plants are using both kinetic and potential energy of water resources. Performance of water power plant:

$$
P=\rho \cdot g \cdot H \cdot Q \quad\left[\mathrm{~W}, \mathrm{~m}^{3} \cdot \mathrm{s}^{-1}, \mathrm{~m}\right]
$$

Or

$$
\begin{aligned}
& P=9,81 \cdot H \cdot Q \quad\left[\mathrm{~kW}, \mathrm{~m}^{3} \cdot \mathrm{s}^{-1}, \mathrm{~m}\right] \\
& Q-\text { flow rate }\left[\mathrm{m}^{3} \cdot \mathrm{s}^{-1}\right], \\
& H \text { - gradient rate }[\mathrm{m}], \\
& g \text { - gravity acceleration }\left[\mathrm{m} \cdot \mathrm{s}^{-2}\right], \\
& \rho \text { - density }\left[\mathrm{kg} \cdot \mathrm{m}^{-3}\right] .[2]
\end{aligned}
$$




\subsection{Advantages and disadvantages of hydropower}

Advantages:

- Once a dam is constructed, electricity can be produced at a constant rate.

- If electricity is not needed, the sluice gates can be shut, stopping electricity generation. The water can be saved for use another time when electricity demand is high.

- Dams are designed to last many decades and so can contribute to the generation of electricity for many years / decades.

- The lake that forms behind the dam can be used for water sports and leisure / pleasure activities. Often large dams become tourist attractions in their own right.

- The lake's water can be used for irrigation purposes.

- The build up of water in the lake means that energy can be stored until needed, when the water is released to produce electricity.

- When in use, electricity produced by dam systems do not produce greenhouse gases. They do not pollute the atmosphere.

Disadvantages:

- Dams are extremely expensive to build and must be built to a very high standard.

- The high cost of dam construction means that they must operate for many decades to become profitable.

- The flooding of large areas of land means that the natural environment is destroyed.

- People living in villages and towns that are in the valley to be flooded, must move out. This means that they lose their farms and businesses. In some countries, people are forcibly removed so that hydro-power schemes can go ahead.

- The building of large dams can cause serious geological damage. For example, the building of Hoover Dam in the USA triggered a number of earth quakes and has depressed the earth's surface at its location.

- Although modern planning and design of dams is good, in the past old dams have been known to be breached (the dam gives under the weight of water in the lake). This has led to deaths and flooding.

- Dams built blocking the progress of a river in one country usually means that the water supply from the same river in the following country is out of their control. This can lead to serious problems between neighboring countries.

- Building a large dam alters the natural water table level. For example, the building of the Aswan Dam in Egypt has altered the level of the water table. This is slowly leading to damage of many of its ancient monuments as salts and destructive minerals are deposited in the stone work from 'rising damp' caused by the changing water table level. [3]

\subsection{Pumped hydroelectric power plants}

The fundamental principle of Pumped hydroelectric power storages (PHES) is to store electric energy in the form of hydraulic potential energy. Pumping typically takes place mainly during off-peak periods, when electricity demand is low and electricity prices are low. Generation takes place during peak periods, when electricity system demand is high. Pumping and generating generally follow a daily cycle but weekly or even seasonal cycling is also possible with larger PHES plant.

Pure PHES plants rely entirely on water that has been pumped to an upper reservoir from a lower reservoir, a river or the sea. Pure PHES are also known as 'closed-loop' or 'off-stream'. Pump-back PHES use a combination of pumped water and natural inflow to produce power/energy similar to a conventional hydroelectric power plant. Pumpback PHES may be located on rivers or valleys with glacial or hydro inflow. [4]

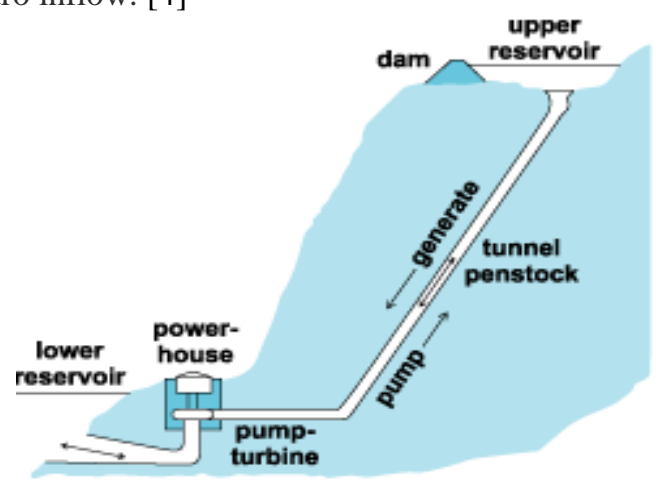

Fig. 1 The scheme of PHES

\section{SIMULATION IN GOLDSIM}

GoldSim is a powerful and flexible Windows-based computer program for carrying out probabilistic simulations of complex systems to support management and decisionmaking in engineering, science and business. The program is highly graphical, highly extensible, able to directly represent uncertainty, and allows you to create compelling presentations of your model. Although GoldSim can be used to solve a wide variety of complex problems, it is particularly well-suited (and was originally developed) to support evaluation of complex environmental systems. Powerful contaminant transport features allow nearly any kind of natural or man-made environmental system to be simulated.

GoldSim is a general purpose simulator that utilizes a hybrid of several simulation approaches, combining an extension of system dynamics with some aspects of discrete event simulation, and embedding the dynamic simulation engine within a Monte Carlo simulation framework.

GoldSim is a powerful and flexible platform for visualizing and numerically simulating nearly any kind of physical, financial or organizational system. In a sense, GoldSim is like a "visual spreadsheet" that allows you to visually create and manipulate data and equations (see Fig. 2). Unlike spreadsheets, however, GoldSim allows you to readily evaluate how systems evolve over time, and predict their future behavior. 
Because simulation can be such a powerful tool for understanding and managing complex systems, a variety of simulation tools currently exist. The following combination of features, however, makes the GoldSim approach unique:

- GoldSim is user-friendly and highly graphical, such that you can literally draw (and subsequently present) a picture (an influence diagram) of your system in an intuitive way without having to learn any arcane symbols or notation.

- GoldSim is extremely flexible, allowing it to be applied to nearly any kind of system. The software allows you to build a model of your system in a hierarchical, modular manner, such that the model can readily evolve as more knowledge regarding the system is obtained. Hence, a GoldSim model can be very simple or extremely complex.

- Uncertainty in processes, parameters and futureevents can be explicitly represented. Uncertainty in processes and parameters can be represented by specifying model inputs as probability distributions. The impact of uncertain events (e.g., earthquakes, floods, sabotage) can also be directly represented by specifying the occurrence rates and consequences of such "disruptive events."

- GoldSim is highly extensible. You can dynamically link external programs or spreadsheets directly into your GoldSim model. In addition, GoldSim was specifically designed to support the addition of customized modules (program extensions) to address specialized applications.

- GoldSim allows you to create compelling presentations of your model. A model which cannot be easily explained is a model that will not be used or believed. GoldSim was specifically designed to allow you to effectively document, explain and present your model. You can add graphics, explanatory text, notes and hyperlinks to your model, and organize it in a hierarchical manner such that it can be presented at an appropriate level of detail to multiple target audiences. [5][6]

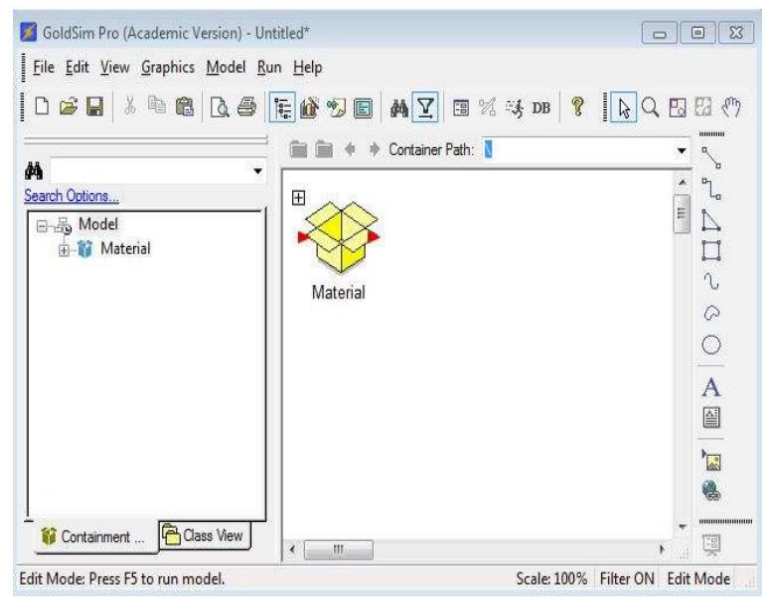

Fig. 2 User interface in GoldSim

\subsection{Simulation of electricity production in hydroelectric power plant}

Performance simulation can also be used for each kind of hydroelectric power plant. It calculates the gross performance of the water source, which depends on the gradient and flow, which are single variables. Performance simulation deals with the size of performances at various flow rates and falls and their updates. It automatically calculates instaneous generating power and quantity of electricity power generation per year for constant parameters.

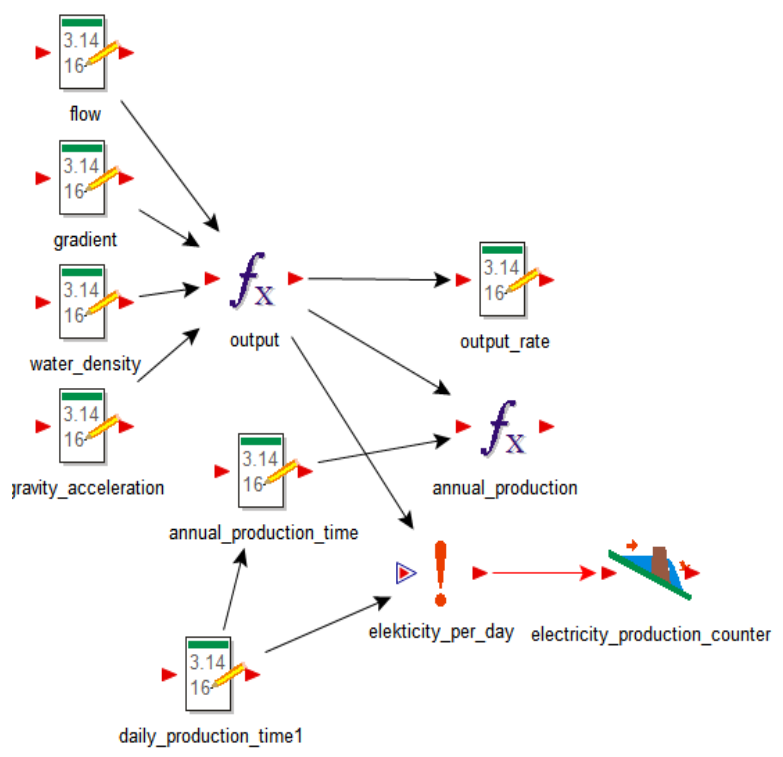

Fig. 3 Program for counting electricity production

Description and value of individual objects in the program is as follows:

- The flow is variable and can be changed fof performance calculations for different hydropower plants. Flow unit is $\mathrm{m}^{3} \cdot \mathrm{s}^{-1}$.

- The gradient of water levels of the PVE tanks is also variable and his unit is $\mathrm{m}$.

- Water density depends on the temperature at a temperature of $3.98^{\circ} \mathrm{C}$ has a maximum value $1000 \mathrm{~kg} / \mathrm{m} 3$, in raising and lowering the density of water is receding .

- Gravity acceleration in our latitude is worth approximately $9.81 \mathrm{~m} . \mathrm{s}^{-2}$.

- Instantaneous power is the function of flow, gradient, water density and gravitational acceleration It's only a rough performance because the real power should also be taken of efficiency of the turbine and generator.

- Daily operating time it's time when turbine is running and generator is connected to the network and producing electricity.

- Annual operating time it's sum of 365 daily operation times.

- Electricity for day shows amount of electricity produced per day and is given in $\mathrm{kWh}$.

- Annual electricity production is the product of the annual operating time and performance. The annual production we numerically expresses the amount of electricity produced per year in $\mathrm{kWh}$.

- Quantity of power produced per year expresses graphically the amount of electricity generated per year in $\mathrm{kWh}$. 


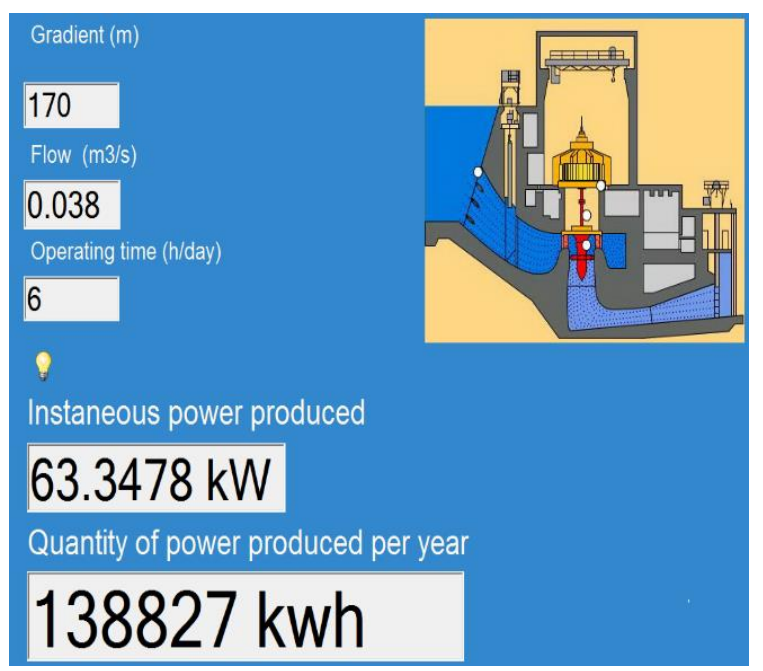

Fig. 4 Graphical user panel of power production

\subsection{Simulation of Water levels balance}

This simulation shows a comparison between the inflow of pumping and drainage of the turbine and daily balances between them. It's based of daily time predicted pumping time and daily turbine generating time with constant value of water inflow and outflow rate. It also contain user window where user simply get predicted values or measured values and result is automatically given.

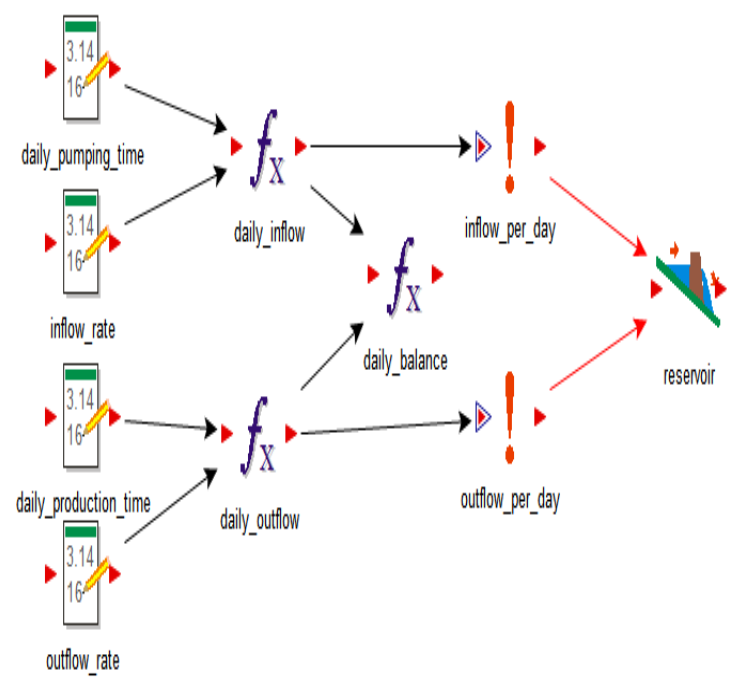

Fig. 5 Program for water states of reservoirs counting

Insert elements are on the left side of diagram and the output elements are on the opposite side.

Meaning of elements:

- Daily time of pumping water is entered in hours and program automatically count amount of water inflow. The resulting value is automatically shown in the window daily inflow to reservoir.

- Daily time of producing is also entered in hours and outflow is showed automatically in window

- Daily inflow is function of daily pumping time and inflow rate.

- Daily outflow is function of daily production time ane outflow rate.
- Reservoir represents daily states of water and counts it

- Daily balance is diference between daily inflow and daily outflow.

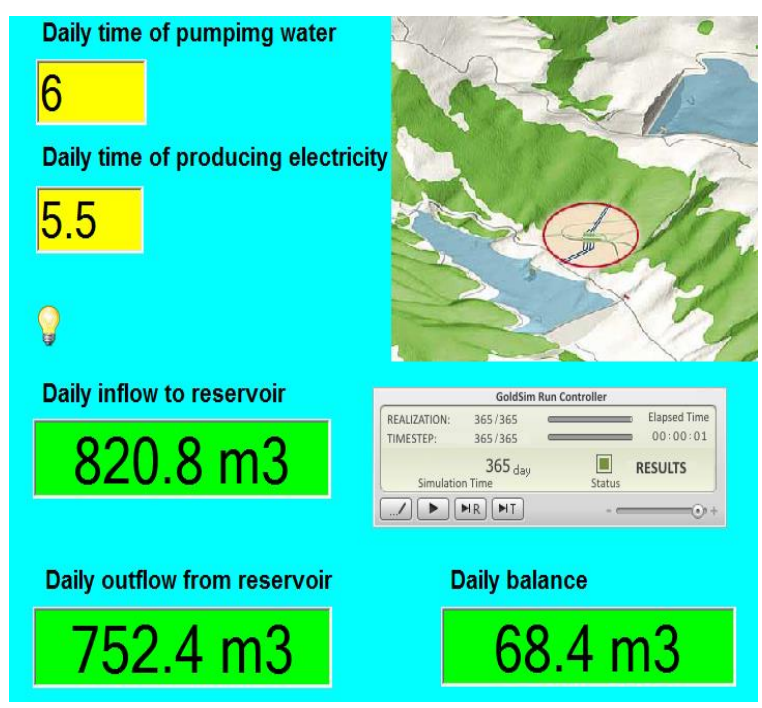

Fig. 6 Graphical user panel of water states

\section{RESULTS}

This model can be used for simulation of gross hydroelectric power plants calculation. It is full automatic and it is very easy to calculate gross output power from various water power plants. It also can simulate and record water balance and states in reservoir of pumped hydroelectric power plant

This model was designed for purpose of calculating and designing project of pumped hydroelectric power plant in area of Bankov mine in Košice.this was main purpose of this work.

Some calculated results with various parameters of gradient flow and daily producing time are shown in Table 1 below.

Table 1 Calculated results from program

\begin{tabular}{|c|c|c|c|c|}
\hline $\begin{array}{c}\text { Gradient } \\
{[\mathrm{m}]}\end{array}$ & Flow & $\begin{array}{c}\text { Daily } \\
\text { producing } \\
\text { time } \\
{\left[\mathrm{m}^{3} \cdot \mathrm{s}^{-1}\right]}\end{array}$ & $\begin{array}{c}\text { Instaneous } \\
\text { power } \\
{[\mathrm{kW}]}\end{array}$ & $\begin{array}{c}\text { Yearly } \\
\text { Production } \\
{[\mathrm{MWh}]}\end{array}$ \\
\hline 170 & 0,38 & 6 & 63,34 & 138,82 \\
\hline 150 & 0,38 & 6 & 55,89 & 122,49 \\
\hline 170 & 0,5 & 6 & 833,52 & 182,66 \\
\hline 170 & 0,38 & 24 & 63,34 & 555,30 \\
\hline
\end{tabular}

\section{CONCLUSIONS}

This work is about calculating various hydroelectric power plants gross output power, but this output power depend also from hydraulic efficiency of water turbine and electric efficiency of generator and transformer. 


\section{ACKNOWLEDGMENTS}

This work was supported by Slovak Research Agency No. VEGA 1/0388/13 project.

\section{REFERENCES}

[1] ARMAROLI. N. - BALZANI. V.: "Energv for a sustainable world" Wiley-VCH, Weinheim, 2011.

[2] CAStronuOvo, E. D. - LOPES PECAS, J. A.: "Optimal operation and hydro storage sizing of a wind-hydro power plant". International Journal of Electrical Power \& Energy Systems, 2004, 26.10: 771-778.

[3] KHENNAS, S. - BARNETT, A.: "Best Practices for Sustainable Development of Micro-Hydro in Developing Countries" ESMAP Technical Paper 006, IBRD, World Bank, 2000.

[4] YANG, Chi-Jen - JACKSON, R. B.: "Opportunities and barriers to pumped-hydro energy storage in the United States". Renewable and Sustainable Energy Reviews, 2011, 15.1: 839-844.

[5] KOSSIK, R. - MILLER, I.: "A propabilistic total system approach to the simulation of complex environmental system" Simulation conference vol,2 pp. 1757-1761, 2004.

[6] GAVANIDOU, E.S. - BAKIRTZIS, A.G. DOKOPOULOS, P.S.: "A probabilistic method for the evaluation of the performance and reliability of wind-diesel energy systems". IEEE Trans Energy Convers 1993;8:197-206.
Received March 20, 2015 , accepted July 6, 2015

\section{BIOGRAPHY}

Miroslav Mikita is a Ph.D. student in the Department of Electric Power Engineering on the Faculty of Electrical Engineering and Informatics at Technical University in Košice. He received a master degree in electric power engineering on subject designing of pumped hydroelectric power plant. His scientific research is mainly focused on research of renewable sources cooperation.

Address: Mäsiarska 74, 04120, Košice, Slovakia

Michal Kolcun was born in 1954 in Ruska Vol'a nad Popradom, Slovakia. In 1979 he graduated at the Faculty of Electric Power Engineering of the Moscow Power Engineering Institute. In 1989 he defended his $\mathrm{PhD}$ on the same institute in Moscow. In 1993 he habilitated to associated professor at the department of Electric Power Engineering on the Faculty of Electrical Engineering and Informatics at Technical University in Košice. In 2000 he inaugurate to professor, his thesis title was High-tension electrical power engineering. Since 2006 he is honorary professor at Budapest Polytechnics. Since 1979 he is working with the Department of Electric Power Engineering on the Faculty of Electrical Engineering and Informatics at Technical University in Košice. His scientific research is focusing on a power system control and computer application in electric power engineering. In addition, he also gives lectures in multiple foreign universities in Moscow, Budapest, Riga, Tallinn, Varna, Prague and Ostrava.

Address: Mäsiarska 74, 04120, Košice, Slovakia 